\title{
A Bibliometric Overview of the International Journal of “Ophthalmology" from 1999-2018
}

\author{
Ajit Prajapati', Neha Munjal'2, Vijay Mohan \\ Soni $^{2}$, Sanjay Kataria ${ }^{3}$, Shiv Singh ${ }^{4}$ \\ ${ }^{1}$ Govt. Arts and Commerce College, Netrang, Gujarat, India \\ ${ }^{2}$ Lovely Professional University, Punjab, India \\ ${ }^{3}$ The BITS School of Management (BITSOM), Mumbai, India \\ ${ }^{4}$ Bennett University (Times of India Group), Uttar Pradesh, India
}

Key words: Web of Science, Scopus, Scientific visualization
Introduction:

Ophthalmology, is the top leading journal of the American Academy of Ophthalmology, with an impact factor of 7.732 . 10,306 documents have been contributed by 21955 authors from 1999-2018. The collaboration index is 2.37 , which clearly signifies that the multiple authorship is dominating. The journal "ophthalmology" serves society by publishing clinical and basic science research and other relevant manuscripts that relate to the sense of sight. The chief purpose of this study is to examine the published articles in context to the leading articles, authors, institutions, and countries. The best suitable method to evaluate the research output is the Bibliometric approach. The analysis of the published content gives an insight into the research trend in the particular field. Thus, this gives a qualitative and quantitative analysis of the journal's contribution to the scientific community. Understanding the trends in research provides valuable insight into the direction of future ophthalmology. The eyesight is a common problem of concern, therefore, several studies related to Ophthalmology has been reported earlier at national and international level.

The aim of this study is to use bibliometric analysis to

\section{Abstract}

The analysis of the most leading journals by the American Academy of Ophthalmology, that serves society by publishing original, unbiased innovation/research/ advancement, new diagnostic/ therapy in the field of ophthalmology including eye diseases, anatomy and physiology of eyes have been reported in various languages. This paper focuses on the pattern of research targeted by the journals. The key factors covered are leading countries, top-notch authors, benchmark institutes or organizations and related. It also offers keywords searched in ophthalmology to give conduit ideas about researched field. These publications comprise the article, biographical-item, correction, editorial material, letter, reprint and review. The topmost organizations were Johns Hopkins University and the University of California System with 561 papers each. While, the developed countries are major contributors to ophthalmic research, but the productivity of some underdeveloped countries is also growing impressively. The research is supported by many funding agencies as the research is going in the direction of glaucoma.

observe the research pattern of the top leading journal "ophthalmology. The investigations were carried out to predict the country, organization, funding agencies, authors contributing the most to the ophthalmic literature and most popular keywords related to this domain.

\section{Materials and methods:}

The Web of Science (WoS) Core Collection, is the most reliable database, which is used to collect the information for the bibliometric analysis. The WOS has an indexing coverage since 1900 and it covers more than 18000 high impact journals, over 180,000 conference proceedings and more than 80 ,ooo books around the world. In the present work, data is extracted from WOS for the leading International clinical journal 'Ophthalmology' during 1999-2018. The collected data were further categorized and abridged with the aid of quantitative and qualitative ways (Using MS Excel and R software). Further, the results were interpreted in context to publication growth of the journal over the years, productive authors in the field, funding organizations, productive countries, etc.

\section{Results:}

An analysis of published data for two decades (1999-2018)

*Corresponding Author: shivsingh2005@gmail.com 
TECHNOSCIENCE ARTICLE

reveals a total production of 10,306, the majority in three languages including English, Spanish and Romanian, of which the English language had been used in almost 99.9\% of publications. These 10,306 publications comprise of articles (6215), letter (3007), editorial (867) correction (127), review (86), biography (3) and reprint (1).

Table 1 represents a year-wise analysis of researched publications in the journal of Ophthalmology for two decades (1999--2018) along with a percentage analysis of the same and the citation received. Publication of researched data in the field of ophthalmology during the study period showed a consistent trend with a minor fluctuation of over $1 \%$ periodically, every 3-4 years. Within the study period, researched-based papers on Ophthalmology received the highest publication in 2001 with a total of 593 papers. During the very first year of the study period, i.e., in 1999, there were around 568 papers (5.5\%) and till 2003, the growth remained almost consistent for a period of five years. During the next three consecutive years, i.e., 2004-2006, publication slowed at 4.5\%, but grew back to almost $5 \%$ during the next two years (2007-2008) and there was a repetition of the cycle. On average $5 \%$ of papers are publishing every year. The maximum citation received are in 1999 i.e. 21383 for 568 papers.

Table-1: Ophthalmological Research publications in the journal for two decades (1999-2018)

\begin{tabular}{llll}
\hline Year & No. of Papers & In $(\%)$ & No. of Citation \\
\hline 1999 & 568 & $5 \cdot 51$ & 21383 \\
2000 & 579 & 5.62 & 19465 \\
2001 & 593 & $5 \cdot 75$ & 19987 \\
2002 & 519 & 5.04 & 18085 \\
2003 & 539 & 5.23 & 20893 \\
2004 & 490 & $4 \cdot 75$ & 19511 \\
2005 & 471 & $4 \cdot 57$ & 18169 \\
2006 & 513 & $4 \cdot 98$ & 19217 \\
2007 & 536 & 5.20 & 19855 \\
2008 & 520 & 5.05 & 20016 \\
2009 & 498 & 4.83 & 18378 \\
2010 & 495 & 4.80 & 16224 \\
2011 & 545 & 5.29 & 17524 \\
2012 & 570 & 5.53 & 16613 \\
2013 & 570 & $5 \cdot 53$ & 13568 \\
2014 & 466 & 4.52 & 12285 \\
2015 & 478 & 4.64 & 7675 \\
2016 & 520 & 5.05 & 5820 \\
2017 & 423 & 4.10 & 2009 \\
2018 & 413 & 4.01 & 723 \\
\hline
\end{tabular}

Twenty top-notch organizations contributing in the Journal of Ophthalmology from various parts of the world over a period of 20 years are listed in Table-2. Johns Hopkins University and the University of California System with 561 (5.44\%) papers each, have been identified as the top-most organizations with the highest production. University of London, University College London, Wilmer Eye Institute and Moorfields Eye Hospital NHS Foundation Trust are the
Ambient Science, 2021: Vol. 08h(1); 20-24 DOI:10.21276/ambi.2021.08h.1.ta02

other top 5 institutes subsequently publishing in ophthalmology. Other upcoming institutes publishing in ophthalmology include Harvard University, Bascom Palmer Eye Institute, Thomas Jefferson University, University of Miami and Singapore National Eye Centre with more than 300 papers, each. Upcoming organizations with almost 200 papers during the study period include the University of Melbourne, University of California, Los Angeles, University of Sydney, Doheny Eye Institute, and National Institutes of Health NIH, USA.

Table-2: Contribution of Top-ranking Organisation in Ophthalmology

\begin{tabular}{|c|c|c|c|}
\hline Rank & Name of Organisation & Total Papers & $\operatorname{In}(\%)$ \\
\hline 1 & Johns Hopkins University & 561 & $5 \cdot 443$ \\
\hline 1 & University of California System & 561 & 5.443 \\
\hline 2 & University of London & 450 & $4 \cdot 366$ \\
\hline 3 & University College London & 385 & 3.736 \\
\hline 4 & Wilmer Eye Institute & 366 & $3 \cdot 55^{1}$ \\
\hline 5 & $\begin{array}{l}\text { Moorfields Eye Hospital } \\
\text { Nhs Foundation Trust }\end{array}$ & 329 & 3.192 \\
\hline 6 & Harvard University & 325 & 3.154 \\
\hline 7 & Bascom Palmer Eye Institute & 303 & 2.94 \\
\hline 8 & Thomas Jefferson University & 289 & 2.804 \\
\hline 9 & University of Miami & 259 & 2.513 \\
\hline 10 & Singapore National Eye Center & 245 & 2.377 \\
\hline 11 & National University of Singapore & 239 & 2.319 \\
\hline 12 & Va Boston Healthcare System & 225 & 2.183 \\
\hline 13 & University of Southern California & 210 & 2.038 \\
\hline 14 & University of Wisconsin System & 208 & 2.018 \\
\hline 15 & University of Wisconsin Madison & 207 & 2.009 \\
\hline 16 & University of Melbourne & 200 & 1.941 \\
\hline 17 & University of California Los Angeles & 199 & 1.931 \\
\hline 18 & University of Sydney & 198 & 1.921 \\
\hline 19 & Doheny Eye Institute & 1971.912 & \\
\hline 201 & National Institutes of Health Nih, USA & 187 & 1.814 \\
\hline
\end{tabular}

Table 3 provides a listing of funding agencies contributing to the Journal of Ophthalmology during the study period along with their percentage share. Around 2,522 studies have been funded with grants / financial aids/supports among which, National Eye Institute (NEI) National Institutes of Health (NIH) is dedicated to vision research and the only institute identified to have contributed enormously during the years in 595 records, accounting for $5.8 \%$ of the total funded papers. The study reveals a positive outlook of research statistics over a period of 20 years as almost 20 funding agencies had been contributing in this field. Other significant agencies contributing funds for research in ophthalmology include Research to Prevent Blindness Inc in New York, Allergan, National Eye Instituteand Alcon.

Table 4 presents a listing of top-ranked authors' contributing in the field of ophthalmology. Twenty topnotch authors had been identified contributing around 1805 records during the study period. Wong TY, Mitchell P, Shields CL, Shields JA and Weinreb RN had been 
contributing enormously with more than 100 records. Seven authors had been contributing in the range of (7898) articles and 1o authors in the range of (54-64) articles.

Table 3. Top-Funding Agencies in Ophthalmology

\begin{tabular}{lll}
\hline Funding Agencies & $\begin{array}{l}\text { Total } \\
\text { Papers }\end{array}$ \\
\hline NeiNihHhs & 595 & $5 \cdot 773$ \\
Research to Prevent Blindness Inc New York & 190 & 1.844 \\
Allergan & 165 & 1.601 \\
National Eye Institute & 149 & 1.446 \\
Alcon & 131 & 1.271 \\
Research to Prevent Blindness & 130 & 1.261 \\
National Institutes of Health & 126 & 1.223 \\
National Institutes of Health Bethesda Maryland & 123 & 1.193 \\
Novartis & 121 & 1.174 \\
National Eye Institute National Institutes of & 113 & 1.096 \\
Health Bethesda Maryland & & \\
Genentech & 108 & 1.048 \\
National Institute for Health Research & 74 & 0.718 \\
Bayer & 70 & 0.679 \\
Pfizer & 70 & 0.679 \\
Medical Research Council & 67 & 0.65 \\
Heidelberg Engineering & 63 & 0.611 \\
Carl Zeiss Meditec & 60 & 0.582 \\
Regeneron & 57 & 0.553 \\
Research to Prevent Blindness New York & 56 & 0.543 \\
Research to Prevent Blindness New York & 54 & 0.524 \\
\hline
\end{tabular}

Table 4. Top-ranked Authors in Ophthalmology Research

\begin{tabular}{llll}
\hline Rank & Name of Authors & No. of Papers & In $(\%)$ \\
\hline 1 & Wong TY & 136 & 1.32 \\
2 & Mitchell P & 121 & 1.174 \\
3 & Shields CL & 120 & 1.164 \\
4 & Shields JA & 113 & 1.096 \\
5 & Weinreb RN & 109 & 1.058 \\
6 & Aung T & 98 & 0.951 \\
7 & Friedman DS & 93 & 0.902 \\
7 & Klein R & 93 & 0.902 \\
8 & Lam DSC & 91 & 0.883 \\
9 & Wang JJ & 83 & 0.805 \\
10 & Jonas JB & 82 & 0.796 \\
11 & Varma R & 78 & 0.757 \\
12 & Klein Bek & 64 & 0.621 \\
13 & Foster CS & 63 & 0.611 \\
14 & Jaffe GJ & 62 & 0.602 \\
15 & Bressler NM & 61 & 0.592 \\
16 & Jabs DA & 60 & 0.582 \\
17 & Medeiros FA & 58 & 0.563 \\
18 & FeuerWJ & 57 & 0.553 \\
19 & Chew EY & 55 & 0.534 \\
20 & LeeAg & 54 & 0.524 \\
20 & Zangwill Lm & 54 & 0.524 \\
\hline & & &
\end{tabular}

In Table 5, top 20 productive countries publishing in the Journal of Ophthalmology have been enlisted, among which the US bagged the top position with an unbeatable 4324 records, counting to around $42 \%$ of the total production of 10,306. The other countries with a production of more than 400 records during the study period following the US include England (724), Australia (491), Japan (444) and Germany (409). India scored the eighth position with 276 records, accounting to $2.68 \%$. People's Republic of China and Canada are almost close to India with 350 and 278 records. Ten countries including Singapore, Italy, The Netherlands, France, Spain, South Korea, Israel, Switzerland, Brazil, and Austria are in the moderate range with over 100--271 records. Taiwan and Saudi Arabia still needs to revive in the competition.

Table-5: Top 20 Most Productive Countries in Ophthalmology

\begin{tabular}{llll}
\hline Rank & Countries/Regions & No. of Papers & In $(\%)$ \\
\hline 1 & USA & 4324 & 41.956 \\
2 & England & 724 & 7.025 \\
3 & Australia & 491 & 4.764 \\
4 & Japan & 444 & 4.308 \\
5 & Germany & 409 & 3.969 \\
6 & Peoples R China & 350 & 3.396 \\
7 & Canada & 278 & 2.697 \\
8 & India & 276 & 2.678 \\
9 & Singapore & 271 & 2.63 \\
10 & Italy & 265 & 2.571 \\
11 & Netherlands & 228 & 2.212 \\
12 & France & 219 & 2.125 \\
13 & Spain & 198 & 1.921 \\
14 & South Korea & 194 & 1.882 \\
15 & Israel & 140 & 1.358 \\
16 & Switzerland & 138 & 1.339 \\
17 & Brazil & 120 & 1.164 \\
18 & Austria & 103 & 0.999 \\
19 & Taiwan & 85 & 0.825 \\
20 & Saudi Arabia & 73 & 0.708 \\
\hline & Tal & &
\end{tabular}

Table 6 reveals a list of 20 frequently occurring keywords in the Journal Ophthalmology by the publisher, title of articles and abstract. Keywords are a concrete expression of the topic under discussion and can be corelated to the significance/occurrence/prevalence of the issue under discussion. The keywords are further segregated in terms of usage by publishers and authors. The most frequently occurring keywords by the publisher

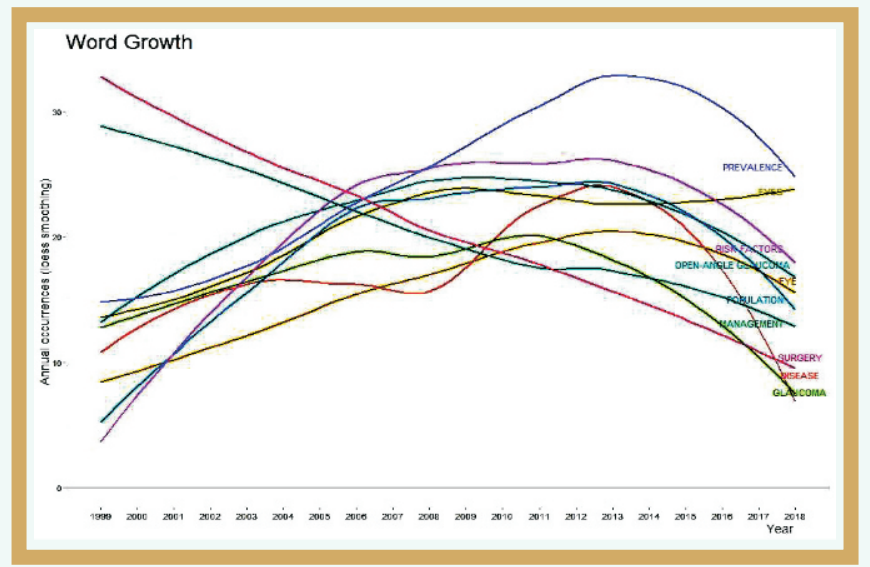

Figure-1: Growth of Top 10 keywords by Author 
TECHNOSCIENCE ARTICLE

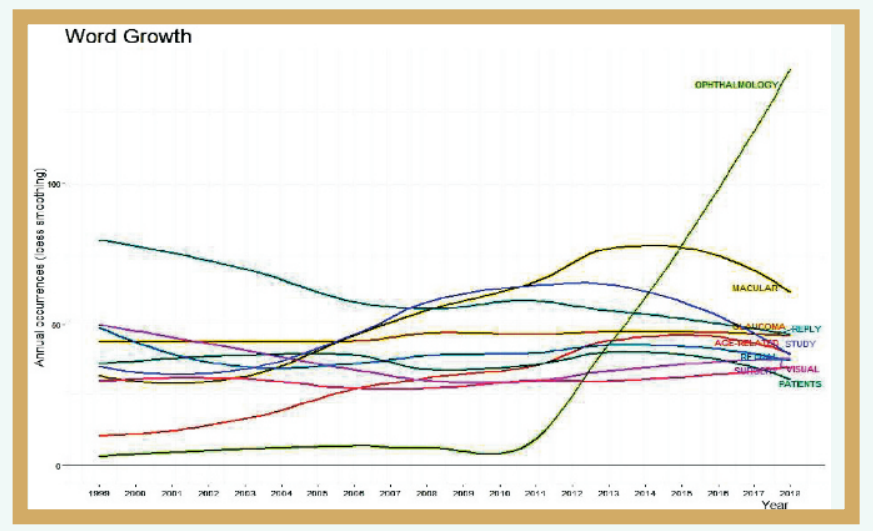

Figure-2: Growth of top 10 keywords from title

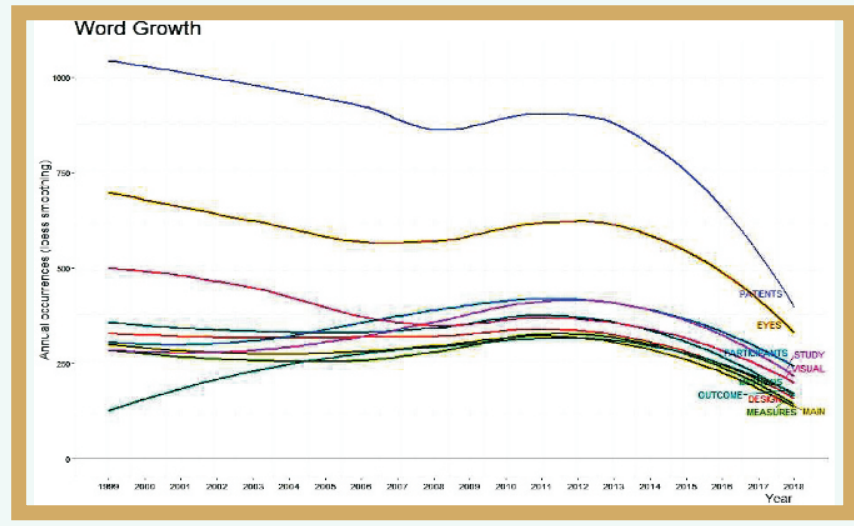

Figure-3: Growth of keywords(term) used in abstract

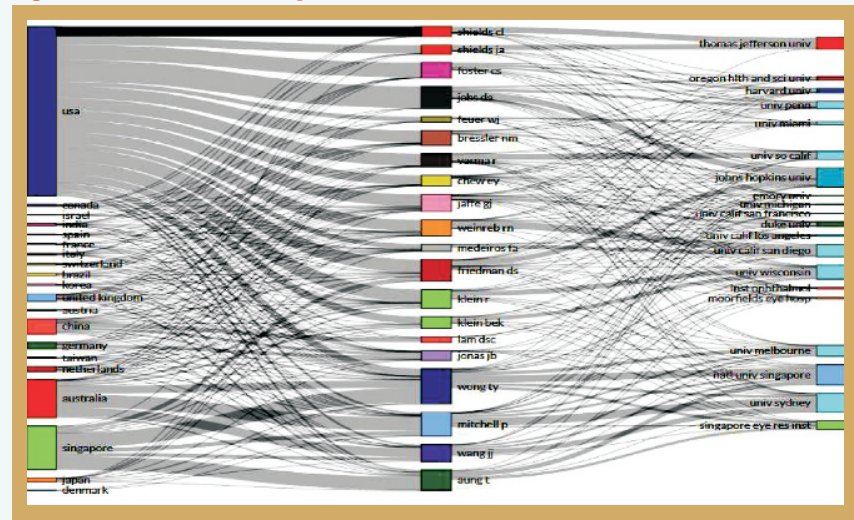

Figure-4: Mapping top 20 countries along with top contributor and top organisations

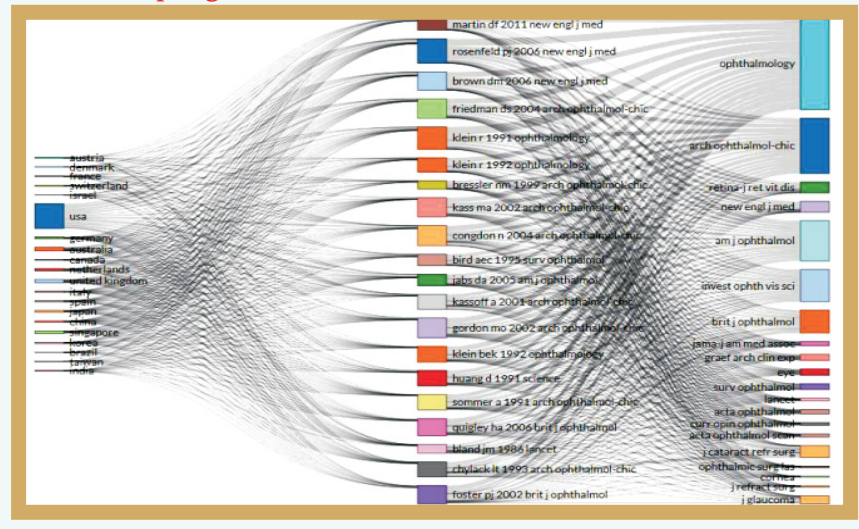

Figure-5: Mapping top 20 countries along with top cited paper and top sources
Ambient Science, 2021: Vol. 08h(1); 20-24 DOI:10.21276/ambi.2021.08h.1.ta02

include prevalence, open-angle glaucoma, management, surgery, eye and risk factors with over 400 occurrences. Author-used words have greater frequency and with around 17336 frequency and the word, 'patient' received the highest frequency of occurrence followed by ophthalmology, eyes, visual, participant and study.

Figure 1-3 reveals a year-wise growth of keywords in ophthalmology during the study period. A positive trend visible from the ground however shows that the term 'surgery' has seen a downward trend since 1999, which may be a positive feat indicating positive development of alternative medicines.

The Figure 4-5. gives the summary of bibliometric indicators in the Ophthalmology literature under consideration. Figure 4 maps the countries with authors and their affiliated universities. Clearly signifying the USA has deep roots in ophthalmology literature. Figure 5 gives the mapping of the top 20 countries along with the topcited paper and sources. Although the USA is in 6th position but has a wider loop.

\section{Conclusion:}

This article offers a bibliographic overview of research published in the Journal of Ophthalmology for the time period (1999-2019). Data for the study is extracted from the WOS and bibliometric indicators are used in the study. A total number of papers published during the last two decades (1999-2018) is 10306. The journal has seen different stages with a moderate impact on the scientific community. The first stage, a period of 5 years (1999-2003) was a drastic year with the highest production in the field, with 2003 producing 593 publications. The growth trend in this field is showing a cyclic pattern with high-moderate-high production. During the last two years of the study period, the publication rate was comparatively moderate, with over 400 papers per year with 2017 producing the lowest publication rate of 413 papers. Analysis of the institutions/organizations and countries reveals Johns Hopkins University and the University of California System with highest publication of 561 papers each. Three other organizations with optimum publication production include the University of London, University College London, Wilmer Institute and Moorfields Eye Hospital NHS Foundation Trust. Leading countries with publication production in the field of ophthalmology include USA, UK, Australia, Japan and Germany with US at the highest production of 4324 papers. Top authors publishing in the field include Wong Ty, Mitchell P., Shields CL, Shields JA and Weinreb RN with Wong TY having the highest production of 136 records. Top funding agencies include The National Eye Institute (NEI), Research to Prevent Blindness, Allergan plc, National Eye Instituteand Alcon. Finally, this bibliometric analysis also has some limitations that should be noted. In future, the data may change, evolve or be modified but the Journal of Ophthalmology must still 
continue to grow and position itself among similar journals, which will definitely encourage researchers to develop a more comprehensive bibliometric analysis involving other complementary methodologies to scientific mapping and continue their effort to support and contribute in this field.

\section{References:}

Baier-Fuentes, H., Cascón-Katchadourian, J., Sánchez, Á.M., Herrera-Viedma, E. \& Merigó, J. (2018): A Bibliometric overview of the International Journal of Interactive Multimedia and Artificial Intelligence. Int. J. Interact. Multimed. Artif. Intell., 5(3)9.

Bharvi, D., Garg, K.C. \& Bali, A. (2003): Scientometrics of the international journal Scientometrics. Scientometrics. 56(1):81-93.

Brown, A., Lush, B. \& Jansen, B.J. (2016): Pixel efficiency analysis: a quantitative web analytics approach. Proc. Asso. Info. Sci. Technol., 53(1):1-10.

Cheng, F.F., Huang, Y.W., Yu, H.C. \& Wu, C.S. (2018): Mapping knowledge structure by keyword co-occurrence and social network analysis: Evidence from Library Hi Tech between 2006 and 2017. Libr. Hi Tech., 36(4):636-650.

Davis, M. \& Wilson, C.S. (2003): Research contributions in ophthalmology: Australia'sproductivity. Clin Exp. Ophthalmol., 31(4):286-2931.

Guerin, M.B., Flynn, T.H., Brady, J. \& O'Brien, C.J. (2009): Worldwide geographical distribution of ophthalmology publications. Int. Ophthalmol., 29:511-516.

Jhamb, G., Meera, \& Singh, K.P. (2019): Indian geology research as reflected by Web of Science during 1998-2017. Collnet. J. Sci. Inf. Manag., 13(1):37-51.
Kumar, M., \& Moorthy, A. (2011): Bibliometric Analysis of DESIDOC Journal of Library and Information Technology from 2001-2010. DESIDOC J. Lib. Info. Technol., 31(3).

Laengle, S., Modak, N.M., Merigó, J.M. \& Sotta, C. De La (2018): Thirty years of the International Journal of Computer Integrated Manufacturing: a bibliometric analysis. Int. J. Comput. Integr. Manuf., 31(12):1247-1268.

Mansour, A.M., Mollayess, G.E., Habib, R., Arabi, A. \& Medawar, W.A. (2015): Bibliometric trends in ophthalmology 19972009. Indian J. Ophthalmol., 63(1):54-58.

Modak, N.M., Merigó, J.M., Weber, R., Manzor, F. \& Ortúzar, J. de D. (2019): Fifty years of transportation research journals: A bibliometric overview.Transp. Res. Part A Policy Pract., 120:188-223.

Ohba, N. (2005): Bibliometric analysis of the current international ophthalmic publications. NipponGanka GakkaiZasshi.,109(3):115-125.

Schlenker, M.B., Manalo, E. \& Wong, A.M. (2013): Research productivity of Canadian ophthalmology departments in top 10 ophthalmology and vision science journals from 2001 to 2010. Can. J. Ophthalmol., 48(1):46-55.

Svider, P.F., Lopez, S.A., Husain, Q., Bhagat, N., Eloy, J.A. \& Langer, P.D. (2014): The association between scholarly impact and national institutes of health funding in ophthalmology. Ophthalmol., 121(1):423-428.

Tur-Porcar, A., Mas-Tur, A., Merigó, J.M., Roig-Tierno, N. \& Watt. J. (2018): A bibliometric history of the journal of psychology between 1936 and 2015. L. Psychol. Interdiscip. Appl., 152(4):199-225. 